\title{
Chromate adsorption on acid-treated and amines-modified clay
}

\author{
M. Hajjaji · A. Beraa
}

Received: 31 August 2013/Accepted: 20 February 2014/Published online: 16 March 2014

(C) The Author(s) 2014. This article is published with open access at Springerlink.com

\begin{abstract}
Acid-treated montmorillonite-rich clay and amines (methylamine, morpholine, and aniline)-modified clay adsorbents were investigated and their abilities to remove chromate from aqueous solution were studied. For the later purpose, kinetic studies were carried out under different operating conditions (chromate concentration, adsorbent content, and temperature), and adsorption isotherm measurements were performed. It was found that the kinetic of adsorption was fast and the data followed the pseudo-second rate equation. The rate of adsorption was controlled by the intra-particle diffusion and mass transfer through the liquid film, and the relative importance of these limiting steps depended on the operating conditions. Chromate adsorption was an endothermic process and took place spontaneously by physisorption. The free energy at $25 \leq T \leq 40{ }^{\circ} \mathrm{C}$ varied from -1.5 to $-46 \mathrm{~kJ} / \mathrm{mol}$. Adsorption isotherms of $\mathrm{Na}^{+}$-saturated clay (AN), acidtreated clay (AA), and methylamine-clay and morpholineclay (A-Me, A-Mo) were type $\mathrm{V}$, whereas those of aniline-clay $(\mathrm{A}-\mathrm{An})$ were type III. The estimated maximum uptakes were $105,29,15,11$, and $10 \mathrm{mmol} / \mathrm{kg}$ for $\mathrm{A}-\mathrm{An}$, AN, A-Mo, AA, and A-Me, respectively. The mechanism of chromate adsorption was discussed based on the shape of the isotherms. Considering for instance the most efficient absorbent (A-An), the isotherm followed the Freundlich equation and hydrogen chromate (the main stable form at working $\mathrm{pH}$ ) adsorbed to solid particles once aniline species were entirely desorbed.
\end{abstract}

M. Hajjaji ( $\square) \cdot$ A. Beraa

LPCME, URAC20, Faculté des Sciences Semlalia,

Université Cadi Ayyad, Bd. Prince My Abdellah, B.P. 2390,

40001 Marrakech, Morocco

e-mail: hajjaji@uca.ma
Keywords Chromate $\cdot$ Amine-modified clay $\cdot$ Adsorption - Kinetics · Isotherms

\section{Introduction}

$\mathrm{Cr}(\mathrm{VI})$-based salts are used in, amongst others, tanning and electroplating industries. Effluents from these industries are loaded with $\mathrm{Cr}(\mathrm{VI})$ compounds such as chromates. As a powerful oxidant, hexavalent chromium is one of the most hazardous substances (Sarkar et al. 2010). Thus, its removal from aqueous solution has received much attention (e.g., Mohan and Pittman 2006).

Swelling clay minerals, particularly those of the smectite group, have high specific surface area and cation exchange capacity. Thereby, they are suitable to remove heavy metals and cationic dyes from aqueous solutions (Murray 2007). However, as negatively polarized minerals, they cannot fix hazardous anionic chemical species, such as chromate, nitrate, arsenate, etc. Retention of anions and improvement of adsorption of cationic pollutants in aqueous solutions using clays were possible by adopting appropriate chemical modifications of clays (acid activation, intercalation, treatment with organic compounds) (e.g., Bergaya and Lagaly 2001; Yariv and Cross 2001; Komadel and Madejová 2006; Lagaly et al. 2006; Lee and Tiwari 2012).

Removal of hexavalent chromium from aqueous solutions by organo-clays has been extensively studied (Atia 2008; Huang et al. 2008; Brum et al. 2010; Zhou et al. 2010; $\mathrm{Hu}$ et al. 2011; Lee et al. 2011). However, less attention was paid to the use of organo-clays with simple amine molecules. Thus, in the present study, amines (methylamine, morpholine, aniline)-modified clay adsorbents were prepared and their potential adsorption of 
chromate from aqueous solutions was tested. The adsorption abilities of sodium-saturated clay and acid-treated clay samples were also investigated. For these purposes, kinetic studies and adsorption isotherm measurements were carried out.

\section{Materials and experimental procedures}

The basic material for sorbents preparation was a naturally occurring clay composed of montmorillonite (88 wt \%), quartz and feldspar ( $9 \mathrm{wt} \%)$, and calcite (3 wt \%). Its specific surface area and cation exchange capacity were $608 \mathrm{~m}^{2} / \mathrm{g}$ and $1.15 \mathrm{meq} / \mathrm{g}$, respectively. It was sieved $(<80 \mu \mathrm{m})$ and saturated with $\mathrm{Na}^{+}$according to the experimental procedure described in Hajjaji et al. (2001).

To prepare the acid-treated clay adsorbent (AA), a clay dispersion composed of $5 \mathrm{~g}$ of clay and $120 \mathrm{~mL}$ of $\mathrm{HCl}$ solution $(6 \mathrm{~N})$ was heated under reflux for $3 \mathrm{~h}$. The sediment was isolated by centrifugation, washed with distilled water and oven-dried.

For the aniline $\left(\mathrm{C}_{6} \mathrm{H}_{5} \mathrm{NH}_{2}\right)$-modified clay (A-An) preparation, $100 \mathrm{~mL}$ of $\mathrm{Na}^{+}$-saturated clay $(10 \mathrm{~g})$ was mixed with a solution of aniline composed of $20 \mathrm{~mL}$ of pure aniline (Janssen Chimica) and $80 \mathrm{~mL}$ of $\mathrm{HCl}$ solution $(1 \mathrm{~N})$. The same experimental procedure was adopted for the preparation of the methylamine $\left(\mathrm{CH}_{3} \mathrm{NH}_{2}\right)$-clay (A$\mathrm{Me})$ and morpholine $\left(\mathrm{C}_{4} \mathrm{H}_{9} \mathrm{NO}\right)$-clay $(\mathrm{A}-\mathrm{Mo})$ adsorbents.

For the study of chromate adsorption kinetic, $40 \mathrm{~mL}$ of potassium chromate solutions $(0.1,0.04$ and $0.02 \mathrm{mmol} / \mathrm{L})$ were mixed with $16 \mathrm{~mL}$ of aqueous solutions of prepared adsorbents $(0.5 \mathrm{~g} / \mathrm{L})$. $\mathrm{pH}$ of the mixture was fixed at four by adding drops of $\mathrm{HCl}(1 \mathrm{M})$ or $\mathrm{NaOH}(1 \mathrm{M})$. The temperature was maintained constant $\left(25,32\right.$ and $\left.40{ }^{\circ} \mathrm{C}\right)$. Each mixture was continuously homogenized by means of a magnetic stirrer $(250 \mathrm{rpm})$. Samples were picked up from the mixture at regular times and subjected to centrifugation. The instantaneous concentration $\left(C_{\mathrm{t}}\right)$ of chromate in the supernatant was determined by UV-visible spectrometry following the method given in Basset et al. (1986), and the adsorbed amount of chromate per mass of adsorbent $\left(q_{\mathrm{t}}\right)$ was calculated: $q_{\mathrm{t}}=\left(C_{\mathrm{o}}-C_{\mathrm{t}}\right) \cdot V / m\left(C_{\mathrm{o}}\right.$ initial concentration of chromate, $V$ volume of chromate solution and $m$ mass of the adsorbent used).

For the adsorption isotherm measurements, $16 \mathrm{~mL}$ of aqueous dispersions ( $0.5 \mathrm{~g}$ of adsorbent per liter) were mixed with $64 \mathrm{~mL}$ of chromate solutions (up to $40 \mathrm{mmol} / \mathrm{L}$ ) and kept at $25{ }^{\circ} \mathrm{C}$ for $4 \mathrm{~h}$. $\mathrm{pH}$ of the mixture was maintained constant as previously mentioned. The supernatant was separated by centrifugation and the content of chromate was measured by UV-visible spectrometry and the uptake amount was deduced using the above relation.
The X-ray diffraction analyses were performed with a PHILIPS X'Pert MPD X-ray diffractometer, using a copper anticathode $\left(K_{\alpha}=1.5418 \AA\right)$. The operating conditions were: generator voltage $40 \mathrm{kV}$, tube current $30 \mathrm{~mA}$, scan step size 0.05 , time/step $0.5 \mathrm{~s}$. The Fourier transform infrared (FT-IR) spectra were recorded with a Perkin Elmer spectrophotometer functioning in the range $4,000-400 \mathrm{~cm}^{-1}$. For this purpose, thin pastilles consisting of $0.02 \mathrm{~g}$ of adsorbents and $0.48 \mathrm{~g}$ of $\mathrm{KBr}$ were prepared.

\section{Results and discussion}

Characterization of the studied adsorbents

As a result of the clay saturation by $\mathrm{Na}^{+}$, the basal distance $\left(d_{001}\right)$ of montmorillonite decreased from 15.7 to $13.2 \AA$ (Fig. 1). This was due to the difference in the size of the hydration spheres of $\mathrm{Na}^{+}(5.6 \AA)$ and $\mathrm{Ca}^{2+}(9.6 \AA)$ (native compensating charge). The interlayer of the methylaminemodified clay also shrunk $\left(\Delta d_{001}=2.6 \AA\right)$. In this case, methylamine species, whose IR bands manifested at 3,034, $2,859,2,761,1,467$ and $1,428 \mathrm{~cm}^{-1}$ (Fig. 2), were tied to clay particles. As far as the infrared analyses are concerned, the bands at 793 and $694 \mathrm{~cm}^{-1}$, and 3,430 and $1,635 \mathrm{~cm}^{-1}$ were assigned to quartz and hygroscopic water (Farmer and Palmieri 1975), respectively. The frequencies at 3,698, 3,624 and $913 \mathrm{~cm}^{-1}$ were related to montmorillonite (Hajjaji et al. 2001). Protonated methylamine was placed in di-trigonal cavities of the sheets of montmorillonite as represented elsewhere (Rowland and Weiss 1961). The manifestation of the extra X-ray reflexions at 3.1 and $6.2 \AA$ (Fig. 1) may be linked to a long-range order of methylamine species within the interlayer space.

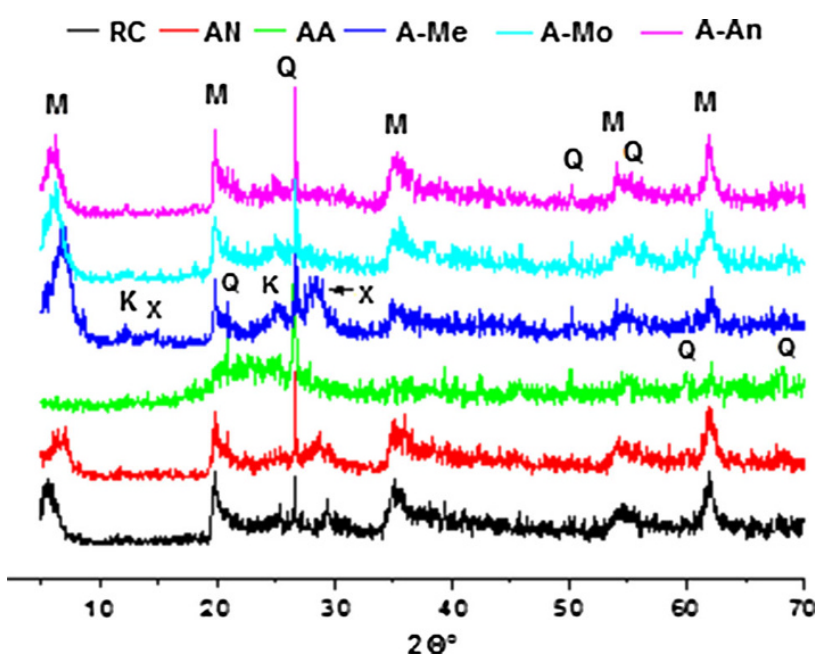

Fig. 1 X-ray diffraction patterns of the raw clay $(\mathrm{RC})$ and the studied adsorbents. $M$ montmorillonite (PDF \# 13-0135), $Q$ quartz (PDF \# 5-0490), $X$ extra reflections 


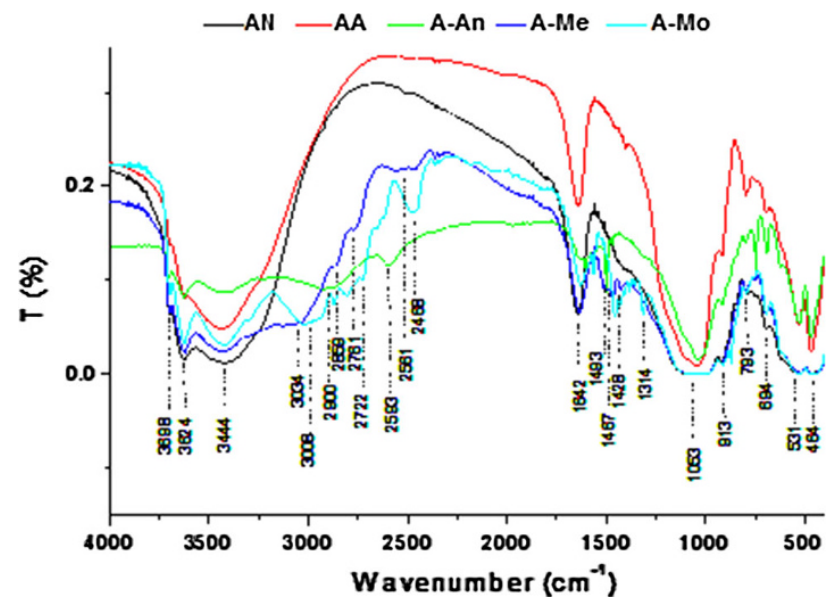

Fig. 2 FT-IR spectra of the prepared adsorbents

Interlayer shrinkages were also recorded for aniline and morpholine modified clay samples $\left(\Delta d_{001}=1.26\right.$ and $1.65 \AA$ for A-An and A-Mo, respectively). It was believed that aniline species vertically placed in the interlayer of montmorillonite and tied to $\mathrm{Na}^{+}$via water molecule (Yariv et al. 1969). Fixed aniline gave rise to the IR bands at 2,900, 2,593, 1,493 $\mathrm{cm}^{-1}$ (Fig. 2). IR frequencies associated to fixed morpholine species manifested at 3,008, $2,865,2,801,2,722,2,468 \mathrm{~cm}^{-1}$ as well as in the range $2,000-400 \mathrm{~cm}^{-1}$ (Fig. 2).

Acid etching of the clay resulted in an almost breakdown of the framework of montmorillonite and the formation of amorphous silica characterized by the X-ray reflection at $16^{\circ}-31^{\circ}$ (Fig. 1) and the IR band at $1,250-1,100 \mathrm{~cm}^{-1}$ (Fig. 2).

Kinetic study

\section{Effects of contact time and changes of concentration of chromate and dose of adsorbent}

Typical curves showing the instantaneous uptake amount of chromate by the studied sorbents are plotted in Fig. 3 . The kinetic of the adsorption of chromate was fast since the maximum uptake limit $\left(q_{\mathrm{e}}\right)$ was reached in $<20 \mathrm{~min}$. $q_{\mathrm{e}}$ evolved linearly as a function of the initial concentration of chromate $\left(q_{\mathrm{e}}=-(0.014 \pm 0.004)+(5.54 \pm 0.06) C_{\mathrm{o}}\right)$. A priori, the driving force in overcoming mass transfer resistance between the aqueous and the solid phases increased with the increase of the initial concentration of chromate.

The kinetic data were analysed using the pseudo-first and pseudo-second kinetic equations $\left(\operatorname{Ln}\left(q_{\mathrm{e}}-\right.\right.$ $\left.q_{\mathrm{t}}\right)=\mathrm{Ln} q_{\mathrm{e}}-k_{1} t$ and $t / q_{\mathrm{t}}=1 / k_{2} q_{\mathrm{e}}^{2}+t / q_{\mathrm{e}}$, respectively, $t$ refers to time, $k_{1}$ and $k_{2}$ are the rate constants). As can be drawn from Table 1, the pseudo-second kinetic equation well described the experimental results. Moreover, $k_{2}$
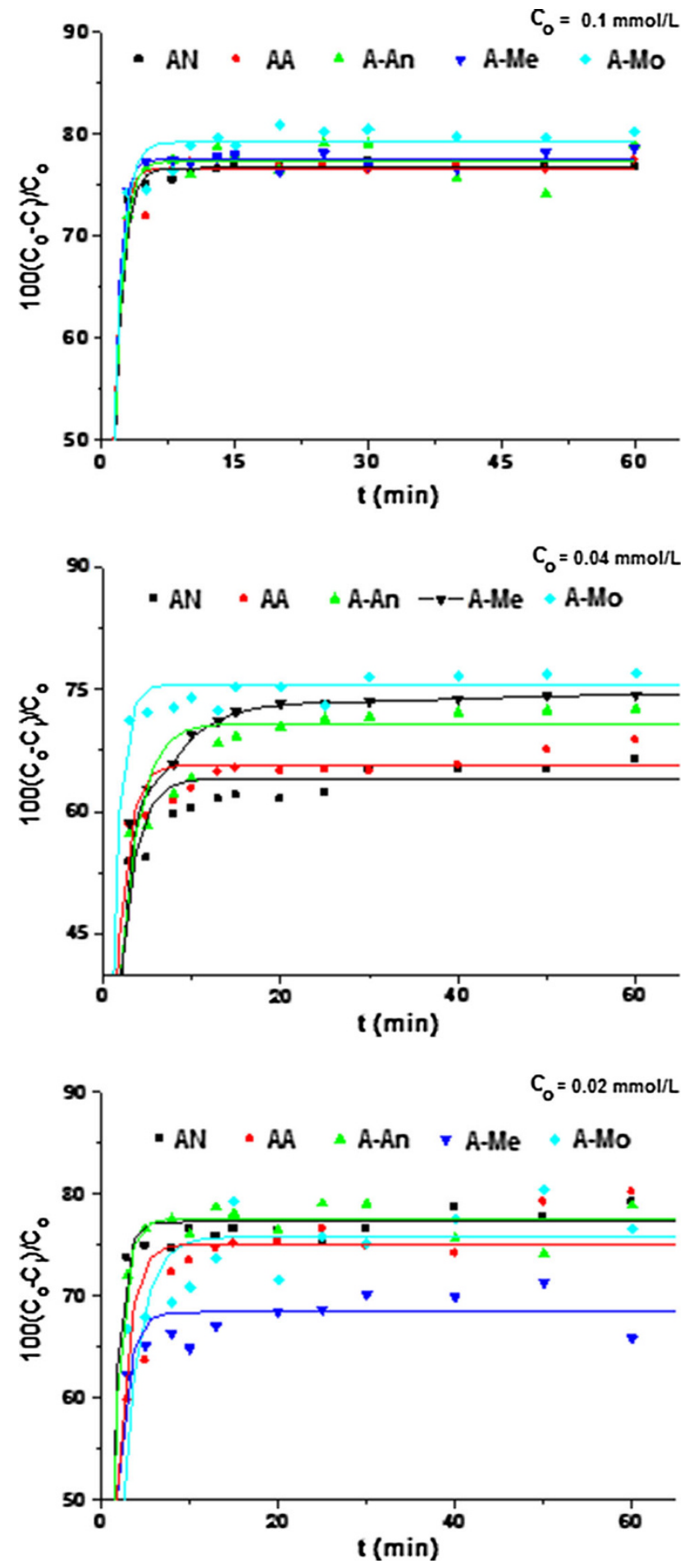

Fig. 3 Kinetic curves related to the adsorption of chromate $\left(C_{\mathrm{o}}=0.1, \quad 0.04\right.$ and $\left.0.02 \mathrm{mmol} / \mathrm{L}\right)$ on the studied sorbents. $\left(T=25^{\circ} \mathrm{C} ; \mathrm{pH} 4\right.$; clay dose $\left.0.5 \mathrm{~g} / \mathrm{L}\right)$

decreased in $0.02-0.06 \mathrm{mmol} / \mathrm{L}$, and increased with further chromate initial concentrations.

The rate-limiting steps were evaluated based on the results of the internal diffusion model $\left(q_{\mathrm{t}}=k_{\mathrm{ip}} t^{0.5}, k_{\mathrm{ip}}\right.$ 
Table 1 Values of the rate constants and fitting coefficients $(R)$ related to the pseudo-first and pseudo-second kinetic equations

\begin{tabular}{|c|c|c|c|c|c|c|c|c|c|c|c|c|}
\hline & \multicolumn{4}{|c|}{$C_{\mathrm{o}}=0.1 \mathrm{mmol} / \mathrm{L}$} & \multicolumn{4}{|c|}{$C_{\mathrm{o}}=0.04 \mathrm{mmol} / \mathrm{L}$} & \multicolumn{4}{|c|}{$C_{\mathrm{o}}=0.02 \mathrm{mmol} / \mathrm{L}$} \\
\hline & \multicolumn{2}{|c|}{$\mathrm{PFKE}^{\mathrm{a}}$} & \multicolumn{2}{|l|}{$\mathrm{PSKE}^{\mathrm{b}}$} & \multicolumn{2}{|c|}{ PFKE } & \multicolumn{2}{|c|}{ PSKE } & \multicolumn{2}{|l|}{ PFE } & \multicolumn{2}{|l|}{ PSE } \\
\hline & $k_{1}$ & $R$ & $k_{2}$ & $R$ & $k_{1}$ & $R$ & $k_{2}$ & $R$ & $k_{1}$ & $R$ & $k_{2}$ & $R$ \\
\hline AN & 0.29 & 0.975 & 9.98 & 0.999 & 0.06 & 0.941 & 4.68 & 0.999 & 0.02 & 0.606 & 96.73 & 0.999 \\
\hline AA & 0.12 & 0.773 & 11.71 & 0.999 & 0.05 & 0.839 & 1.84 & 0.999 & 0.06 & 0.814 & 12.21 & 0.999 \\
\hline A-An & 0.15 & 0.826 & 6.10 & 0.999 & 0.08 & 0.972 & 4.77 & 0.999 & 0.09 & 0.876 & 7.36 & 0.998 \\
\hline $\mathrm{A}-\mathrm{Me}$ & 0.04 & 0.382 & 117.74 & 0.999 & 0.10 & 0.951 & 4.68 & 0.999 & 0.08 & 0.962 & 19.41 & 0.999 \\
\hline A-Mo & 0.11 & 0.788 & 4.39 & 0.999 & 0.07 & 0.866 & 4.70 & 0.999 & 0.04 & 0.898 & 16.19 & 0.998 \\
\hline
\end{tabular}

${ }^{a}$ Pseudo-first kinetic equation

b Pseudo-second kinetic equation

Table 2 Values of the parameters of the internal diffusion and the liquid film mass transfer diffusion models calculated for different concentrations of chromate, and the correlation coefficients of the models

\begin{tabular}{lllllll}
\hline \multicolumn{7}{c}{$q_{\mathrm{t}} k_{\mathrm{ip}} t^{0.5}+C$} \\
\hline$C_{\mathrm{o}}(\mathrm{mmol} / \mathrm{L})$ & & AN & AA & A-An & A-Me & A-Mo \\
\hline 0.02 & $k_{\text {ip }}$ & 0.002 & 0.011 & 0.006 & 0.005 & 0.007 \\
& $C$ & 0.100 & 0.067 & 0.080 & 0.079 & 0.079 \\
& $R$ & 0.882 & 0.954 & 0.900 & 0.845 & 0.910 \\
0.04 & $k_{\text {ip }}$ & 0.018 & 0.010 & 0.017 & 0.018 & 0.007 \\
& $C$ & 0.134 & 0.146 & 0.128 & 0.134 & 0.181 \\
& $R$ & 0.992 & 0.992 & 0.984 & 0.992 & 0.901 \\
0.1 & $k_{\text {ip }}$ & 0.010 & 0.022 & 0.017 & 0.009 & 0.019 \\
& $C$ & 0.499 & 0.462 & 0.486 & 0.512 & 0.484 \\
& $R$ & 0.975 & 0.930 & 0.826 & 0.806 & 0.938 \\
& & $-\mathrm{Ln}(1-F(t))=$ & $k_{\mathrm{ld}} t$ & & \\
0.02 & $k_{\text {ld }}$ & 0.042 & 0.108 & 0.076 & 0.089 & 0.037 \\
& $R$ & 0.797 & 0.918 & 0.758 & 0.942 & 0.739 \\
0.04 & $k_{\text {ld }}$ & 0.032 & 0.037 & 0.093 & 0.108 & 0.062 \\
& $R$ & 0.874 & 0.932 & 0.980 & 0.956 & 0.756 \\
& $k_{\text {ld }}$ & 0.296 & 0.434 & 0.219 & 0.156 & 0.171 \\
& $R$ & 0.975 & 0.925 & 0.845 & 0.813 & 0.957 \\
\hline \multirow{3}{*}{0.1} & & & & & &
\end{tabular}

intra-particle diffusion constant) and the liquid film mass transfer diffusion model $\left(\operatorname{Ln}(1-F(t))=-k_{\mathrm{ld}} t ; F(t)=q_{\mathrm{t}} /\right.$ $q_{\mathrm{e}} ; k_{\mathrm{ld}}$ liquid film diffusion constant) (Qiu et al. 2009). The fitting coefficients and the values of the parameters of the models are reported in Table 2. Satisfactory fits were observed with the use of internal diffusion model, but the linear curves did not pass through the origin $(C \neq 0)$. So, secondary processes (film transfer, electrostatic interactions between chromate and sorbent active sites) were probably involved in the control of the kinetic rate. Referring once again to the results of Table 2, the resistance to the mass transfer diffusion across the liquid film could not be neglected for some adsorbents and initial concentrations of chromate. Moreover, the effect of the
Table 3 Values of the parameters of the internal diffusion and the liquid film mass transfer diffusion models calculated for different doses of the adsorbents, and the correlation coefficients of the models

\begin{tabular}{lllllll}
\hline \multicolumn{7}{c}{$q_{\mathrm{t}}=k_{\mathrm{ip}} t^{0.5}+C$} \\
\hline Adsorbent $(\mathrm{g} / \mathrm{L})$ & & AN & AA & A-An & A-Me & A-Mo \\
\hline \multirow{2}{*}{0.2} & $k_{\text {ip }}$ & 0.007 & 0.014 & 0.003 & 0.023 & 0.018 \\
& $C$ & 0.427 & 0.391 & 0.445 & 0.395 & 0.440 \\
& $R$ & 0.528 & 0.859 & 0.673 & 0.837 & 0.917 \\
0.5 & $k_{\text {ip }}$ & 0.012 & 0.009 & 0.016 & 0.018 & 0.007 \\
& $C$ & 0.129 & 0.152 & 0.135 & 0.134 & 0.182 \\
& $R$ & 0.963 & 0.992 & 0.984 & 0.992 & 0.898 \\
\multirow{4}{*}{1} & $k_{\text {ip }}$ & 0.004 & 0.002 & 0.002 & 0.003 & 0.002 \\
& $C$ & 0.077 & 0.08727 & 0.098 & 0.092 & 0.099 \\
& $R$ & 0.989 & 0.987 & 0.723 & 0.885 & 0.762 \\
& & $-\mathrm{Ln}(1-F(t))=k_{\mathrm{ld}} t$ & & \\
0.2 & $k_{\mathrm{ld}}$ & 0.090 & 0.041 & 0.288 & 0.176 & 0.123 \\
& $R$ & 0.910 & 0.860 & 0.327 & 0.902 & 0.865 \\
0.5 & $k_{\mathrm{ld}}$ & 0.067 & 0.099 & 0.076 & 0.158 & 0.056 \\
& $R$ & 0.887 & 0.926 & 0.758 & 0.995 & 0.699 \\
& $k_{\text {ld }}$ & 0.004 & 0.060 & 0.088 & 0.190 & 0.109 \\
& $R$ & 0.986 & 0.979 & 0.515 & 0.896 & 0.543 \\
\hline & & & & & &
\end{tabular}

boundary layer diffusion, characterized by the magnitude of the constant $C$, increased with the increase of $C_{\mathrm{o}}$.

The change of the clay dose had an effect on the equilibrium time, which varied in the span 5-100 min. High equilibrium times were observed for lower clay doses. The pseudo-second rate equation still described the kinetic data $(R>0.999)$. The rate constants were in the ranges 1-9, 4-8 and $7-70 \mathrm{mmol} / \mathrm{g}$ min for $0.2,0.5$ and $1 \mathrm{~g} / \mathrm{L}$, respectively. The application of the above models (Table 3 ) showed that neither the intra-particle diffusion nor the liquid film diffusion was the sole rate-limiting step. Considering for instance $\mathrm{AN}, \mathrm{AA}$ and A-Me adsorbents, the liquid film diffusion was the main rate-limiting step for the diluted solution $(0.2 \mathrm{~g} / \mathrm{L})$. However, the internal diffusion was almost the predominant mechanism for solutions containing 0.5 and $1 \mathrm{~g} / \mathrm{L}$. 
Considering the values of $C$ (Table 3 ), the thickness of the liquid film increased with the use of low dose of adsorbent. Likely because of this fact the adsorption kinetic was limited by liquid film mass transfer diffusion. In this respect, it may be noted that low correlation coefficients for both models were obtained. It seemed that adsorption rate was partially controlled by the interaction between chromate species and adsorbent active sites.

\section{Effect of temperature and thermodynamic parameters}

The change of temperature had no appreciable effect on the equilibrium time, and the kinetic data still followed the pseudo-second kinetic relation. The rate kinetic constants are given in Table 4. $k_{2}$ evolved linearly as a function of $1 /$ $T(K)$ only for $\mathrm{AN}$ and the activation energy in this case was estimated to $8.19 \mathrm{~kJ} / \mathrm{mol}$.

The results of the aforementioned models (not reported) showed that adsorption kinetic was not wholly controlled by the intra-particle diffusion or by the liquid film mass transfer diffusion. Mechanisms involving interactions

Table 4 Rate constants $\left(k_{2}\right)$ at different operating temperatures

\begin{tabular}{lllrll}
\hline$T\left({ }^{\circ} \mathrm{C}\right)$ & AN & AA & \multicolumn{1}{c}{ A-An } & A-Me & A-Mo \\
\hline 25 & 4.168 & 7.720 & 4.177 & 6.815 & 7.078 \\
32 & 4.742 & 3.854 & 15.361 & 4.582 & 5.945 \\
40 & 5.996 & 7.040 & 5.837 & 6.604 & 5.337 \\
\hline
\end{tabular}

Table 5 Thermodynamic data of chromate adsorption on the sorbents studied

\begin{tabular}{llcll}
\hline & $T\left({ }^{\circ} \mathrm{C}\right)$ & $\Delta G^{\circ}(\mathrm{kJ} / \mathrm{mol})$ & $\begin{array}{l}\Delta H^{\circ}(\mathrm{kJ} / \mathrm{mol}) \\
\text { intercept of } \\
\Delta G^{\circ}=\Delta H^{\circ} \\
-T \Delta S^{\circ}\end{array}$ & $\begin{array}{l}\Delta S^{\circ}(\mathrm{J} / \mathrm{K} \mathrm{mol}) \\
\text { slope of } \\
\Delta G^{\circ}=\Delta H^{\circ} \\
-T \Delta S^{\circ}\end{array}$ \\
\hline AN & 25 & -1.588 & 12.681 & -47.885 \\
& 32 & -16.193 & & \\
& 40 & -31.181 & & -71.195 \\
AA & 25 & -1.848 & 19.368 & \\
& 32 & -2.3563 & & -48.771 \\
& 40 & -45.847 & & \\
A-An & 25 & -2.491 & 12.042 & -50.097 \\
& 32 & -17.366 & & \\
& 40 & -32.632 & & -24.431 \\
A-Me & 25 & -2.720 & 12.208 & \\
& 32 & -18.000 & & \\
& 40 & -33.680 & & \\
A-Mo & 25 & -3.025 & 4.255 & \\
& 32 & -10.476 & & \\
& 40 & -18.123 & & \\
\hline
\end{tabular}

between chromate species and adsorbent particles were likely predominant at high temperature.

Thermodynamic values related to chromate adsorption on the studied adsorbents are shown in Table 5 . Based on the algebraic values of $\Delta G_{\mathrm{T}}^{\circ}\left(\Delta G_{\mathrm{T}}^{\circ}=-R T \operatorname{Ln} K_{\mathrm{e}}, R\right.$ gas constant, $T$ temperature and $K_{\mathrm{e}}$ the equilibrium constant $\left.\left(K_{\mathrm{e}}=q_{\mathrm{e}} / C_{\mathrm{e}}\right)\right)$ chromate adsorption took place spontaneously. The spontaneity of the process improved with the increase of temperature. Chromate adsorption was an endothermic process $\left(\Delta H^{\circ}>0\right)$ and occurred by physisorption $\left(\Delta H^{\circ}<40 \mathrm{~kJ} / \mathrm{mol}\right.$ ) (Shiau and Pan 2004). Considering the algebraic values of $\Delta S^{\circ}$, the fixation of chromate to adsorbent particles corresponded to a relatively ordered state.

Isotherm measurements and adsorption mechanisms

Adsorption isotherms related to the studied adsorbents are depicted in Fig. 4. They were categorized as type V, except that of A-An, which identified to type III. The later isotherm expressed the presence of weak interactions at low concentrations of chromate, and the development of attractive forces at high concentrations. Similar phenomena took place for the other studied systems. However, in the later cases the accumulation of adsorbate species reached a limit revealed by the occurrence of a plateau.

Adsorption took place on heterogeneous sites and multilayers of chromate built around adsorbent particles, developing thus mutual interactions. Therefore, the isotherms did not follow the Langmuir equation $\left(q_{\mathrm{e}}=K_{\mathrm{L}}\right.$ $C_{\mathrm{e}} q_{\mathrm{m}} /\left(1+K_{\mathrm{L}} C_{\mathrm{e}}\right), K_{\mathrm{L}}$ Langmuir constant, $q_{\mathrm{m}}$ maximum uptake). The correlation coefficients were in the range $0.157-0.883$. Conversely, the isotherms were quite described with the Freundlich equation $\left(q_{\mathrm{e}}=K_{\mathrm{F}} C_{\mathrm{e}}^{1 / n} ; K_{\mathrm{F}}\right.$ and $n$ are constants). The values of the constants and the fitting coefficients are reported in Table 6.

In the operating acid medium ( $\mathrm{pH} 4)$, hydrogen chromate (the most predominant ion) and positively polarized silanol and aluminol groups of montmorillonite developed attractive forces. Thereby, favourable adsorption occurred for AN. The same mechanism could happen in the case of AA. Nevertheless, the contribution of the amorphous silica to the adsorption process of chromate seemed to be insignificant. It may be noted that the infrared analyses (Fig. 5) had not manifest bands associable to chromate or its deriving species.

The shape of the isotherm of A-Me is explained by the presence of two consecutive processes: at low concentrations of chromate (initial plateau), $\mathrm{HCrO}_{4}{ }^{-}$developed electrostatic attraction with $\mathrm{CH}_{3} \mathrm{NH}_{3}{ }^{+}$tied to clay particles and the plausible acid-base reaction between the two species was discarded since $\mathrm{Ka}\left(\mathrm{H}_{2} \mathrm{CrO}_{4} / \mathrm{HCrO}_{4}{ }^{-}\right)>\mathrm{Ka}\left(\mathrm{CH}_{3} \mathrm{NH}_{3}{ }^{+}\right.$/ 

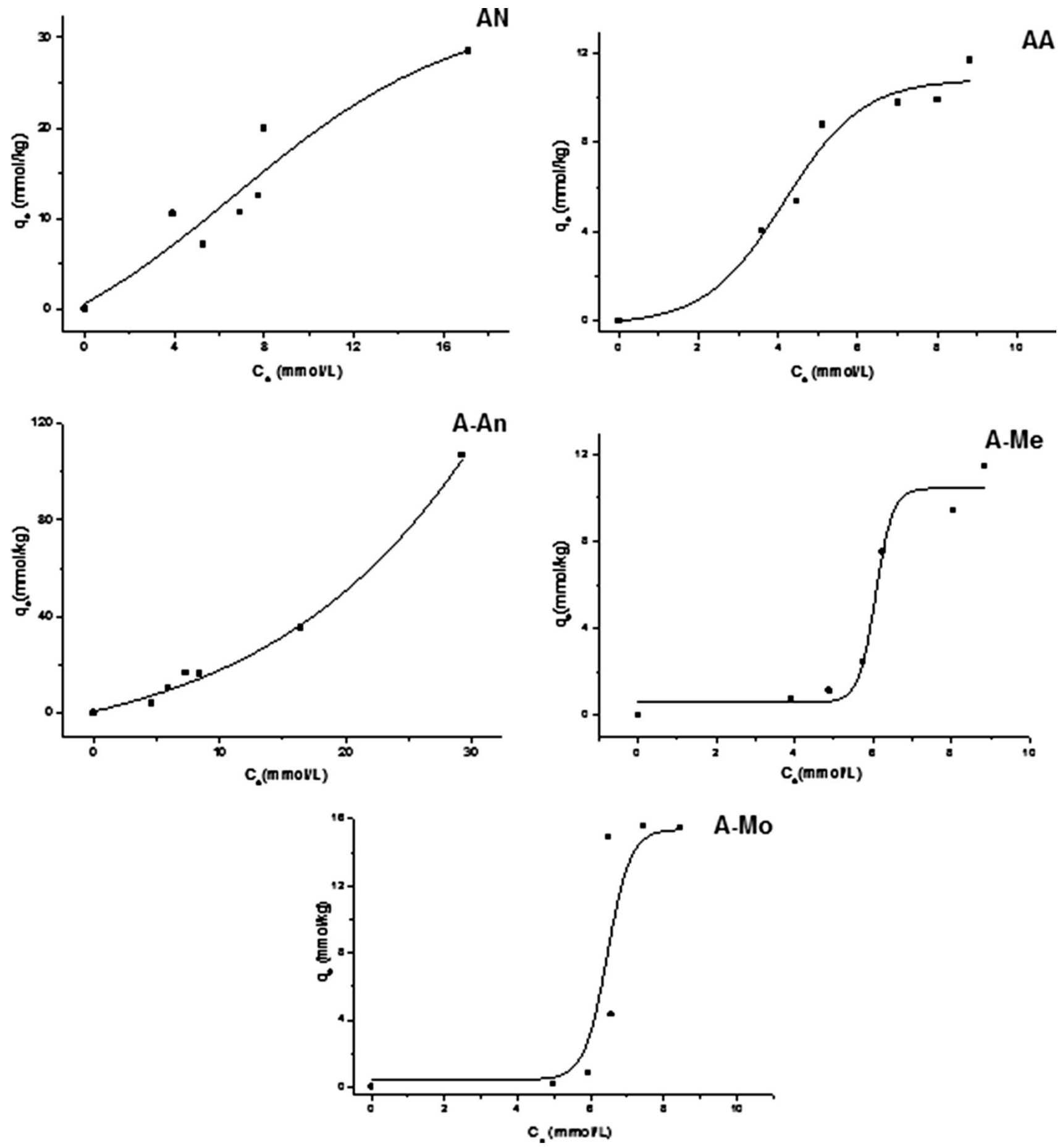

Fig. 4 Adsorption isotherms related to the studied adsorbents. $T=25{ }^{\circ} \mathrm{C}$

$\mathrm{CH}_{3} \mathrm{NH}_{2}$ ). As the ions of $\mathrm{CH}_{3} \mathrm{NH}_{3}{ }^{+}$were totally desorbed, $\mathrm{HCrO}_{4}{ }^{-}$fixed intensively to clay particles, which resulted in the sharp increase of the uptake. The total release of $\mathrm{CH}_{3} \mathrm{NH}_{3}{ }^{+}$from A-Me was evidenced by infrared spectroscopy analyses (Fig. 5). Similar adsorption processes happened with A-Mo. Nevertheless, in this case only a partial amount of morpholine was desorbed as revealed by the reduction of the intensities of infrared bands relevant to morpholine bonds (Fig. 5). Regarding the adsorption behavior of A-An and based on the IR spectra of Figs. 2 and 5 , aniline remained fixed to clay particles after chromate adsorption. Thus, the exceptional increasing uptake of hydrogen chromate could be linked to the implication of the electronic cloud of the aromatic ring. 
Table 6 Values of the parameters of the Freundlich equation and fitting coefficients determined for the studied sorbents

\begin{tabular}{llll}
\hline & $1 / n$ & $K_{\mathrm{F}}$ & $R$ \\
\hline AN & 0.85 & 2.47 & 0.97 \\
AA & 1.09 & 1.13 & 0.94 \\
A-An & 1.58 & 0.51 & 0.97 \\
A-Me & 3.60 & $5.3 \times 10^{-3}$ & 0.95 \\
A-Mo & 8.96 & $1.8 \times 10^{-7}$ & 0.89 \\
\hline
\end{tabular}

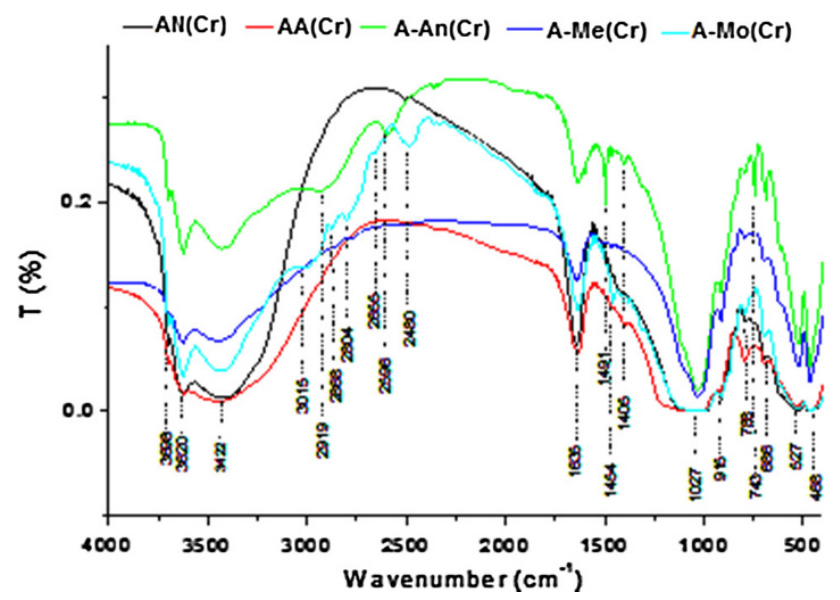

Fig. 5 FT-infrared spectra of the sorbents after contact with chromate

\section{Conclusions}

In acid solutions ( $\mathrm{pH} 4$ ), hydrogen chromate rapidly and spontaneously fixed to positively polarized montmorillonite particles of $\mathrm{Na}^{+}$-saturated clay and acid-treated clay. The adsorption kinetic followed the pseudo-second order equation, and was limited by internal diffusion and/or adsorbate external transfer, depending on chromate concentration, clay amount and temperature. The adsorption isotherms fairly obeyed the Freundich equation and the maximum uptake limit for the acid-modified clay was about the third of that estimated for $\mathrm{Na}^{+}$-saturated clay $(29 \mathrm{mmol} / \mathrm{kg}$ ) because of a partial breakdown of the framework of montmorillonite.

The kinetic behavior of chromate adsorption by methylamine-clay, aniline-clay and morpholine-clay was similar to that manifest by $\mathrm{Na}^{+}$-saturated and acid-etched clay samples, and their relative adsorption isotherms also followed the Freundlich equation. The uptake limit of chromate increased in the following order: A-An $>$ A-Me $>$ A-Mo. The disparities were essentially linked to the relative ability of hydrogen chromate to desorb amine species.

Open Access This article is distributed under the terms of the Creative Commons Attribution License which permits any use, distribution, and reproduction in any medium, provided the original author(s) and the source are credited.

\section{References}

Atia AA (2008) Adsorption of chromate and molybdate by cetylpyridinium bentonite. Appl Clay Sci 41:73-84

Basset J, Denny RC, Jeffery GH, Mendham J (1986) Vogel's textbook of quantitative inorganic analysis. ELBS/Longman, London

Bergaya F, Lagaly G (2001) Surface modification of bentonite minerals. Appl Clay Sci 19:1-3

Brum MC, Capitaneo JL, Oliveira JF (2010) Removal of hexavalent chromium from water by adsorption onto surfactant modified montmorillonite. Miner Eng 23:270-272

Farmer VC, Palmieri F (1975) The characterization of soil minerals by infrared spectroscopy. In: Gieseking JE (ed) Soil components: inorganic components. Springer, New York, pp 573-670

Hajjaji M, Kacim S, Alami A, El Bouadili A, El Mountassir M (2001) Chemical and mineralogical characterization of a clay taken from the Moroccan Meseta and a study of the interaction between its fine fraction and methylene blue. Appl Clay Sci 20:1-12

Hu B, Luo H, Chen H, Dong T (2011) Adsorption of chromate and para-nitrochlorobenzene on inorganic-organic montmorillonite. Appl Clay Sci 51:198-201

Huang Y, Ma X, Liang G, Yan Y, Wang S (2008) Adsorption behavior of $\mathrm{Cr}(\mathrm{VI})$ on organic-modified rectorite. Chem Eng $\mathrm{J}$ 138:187-193

Komadel P, Madejová J (2006) Acid activation of clay minerals. In: Bergaya F, Theng BKG, Lagaly G (eds) Handbook of clay science, development in clay science, vol 1. Elsevier, Netherlands, pp 263-288

Lagaly G, Ogawa M, Dékany I (2006) Clay mineral organic interactions. In: Bergaya F, Theng BKG, Lagaly G (eds) Handbook of clay science, developments in clay science. Elsevier, Netherlands, pp 309-377

Lee SM, Tiwari D (2012) Organo and inorgano-organo-modified clays in the remediation of aqueous solutions: an overview. Appl Clay Sci 59-60:84-102

Lee Y-C, Park W-K, Yang J-W (2011) Removal of anionic metals by amino-organoclay for water treatment. J Hazard Mater 190:652-658

Mohan D, Pittman CU (2006) Review: activated carbons and low cost adsorbents for remediation of tri- and hexavalent chromium from water. J Hazard Mater B137:762-811

Murray H (2007) Applied clay mineralogy: occurrences, processing and applications of kaolins, bentonites, palygorskite, sepiolite, and common clays. Elsevier, Netherlands

Qiu H, Lv L, Pan B-C, Zhang Q-J, Zhang W-M, Zhang Q-X (2009) Critical review in adsorption kinetic models. J Zhejiang Univ Sci A 10(5):716-724

Rowland RA, Weiss EJ (1961) Bentonite-methylamine complexes. Clays Clay Miner 10(1):460-468

Sarkar B, Xi Y, Megharaj M, Krishnamurti GSR, Rajarathnam D, Naidu R (2010) Remediation of hexavalent chromium through adsorption by bentonite based Arquad ${ }^{\circledR}$ 2HT-75 organoclays. J Hazard Mater 183:87-97

Shiau CY, Pan CC (2004) Adsorption of basic dyes from aqueous solution by various adsorbents. Separation Sci Technol 39:1733-1750

Yariv S, Cross H (2001) Organo-clay complexes and interactions. Marcel Dekker Inc, New York

Yariv S, Heller L, Kaufherr N (1969) Effect of acidity in montmorillonite interlayers on the sorption of aniline derivatives. Clays Clay Miner 17:301-308

Zhou J, Wu P, Dang Z, Zhu N, Li P, Wu J, Wang X (2010) Polymeric $\mathrm{Fe} / \mathrm{Zr}$ pillared montmorillonite for the removal of $\mathrm{Cr}(\mathrm{VI})$ from aqueous solutions. Chem Eng J 162:1035-1044 